\title{
TÉCNICAS HEMOTERÁPICAS EM CIRURGIA RENAL PERCUTÂNEA EM PACIENTE TESTEMUNHA DE JEOVÁ
}

\section{UTILIZATION OF HEMOTHERAPIC TECHNIQUES IN PERCUTANEOUS RENAL SURGERY IN JEHOVA'S WITNESS PATIENT}

\author{
Helio Begliomini, TCBC-SP' ${ }^{\text {; Bruno Dal Sasso Begliomini }}{ }^{2}$
}

\section{INTRODUÇÃO}

Os pacientes pertencentes à religião das Testemunhas de Jeová não aceitam em hipótese alguma receber as transfusões de sangue total, de elementos figurados isolados (hemácias, leucócitos ou plaquetas), ou mesmo de plasma sanguíneo, ainda que autólogas com sangue previamente armazenado, ou de si para outras pessoas.

O artigo em questão tenciona divulgar duas técnicas hemoterápicas mais utilizadas em cirurgias cardiovasculares (revascularização do miocárdio, trocas valvulares, correção cirúrgica do aneurisma da aorta...), ortopédicas (prótese total de quadril e joelho) e transplante hepático, e que devem ser sempre recomendadas a pacientes candidatos a cirurgia sangrante, independentemente da crença religiosa professada pelos pacientes ${ }^{1}$. Numa delas, descreve-se variação técnica para a cirurgia renal percutânea.

\section{RELATO DO CASO}

Paciente de 32 anos, feminina, caucasiana, pertencente à religião das Testemunhas de Jeová, apresentava cálculo coraliforme completo no rim direito, assintomática que foi detectado em check-up de rotina. Seus exames pré-operatórios encontravam-se normais, inclusive a urocultura que foi negativa.

Devido à idade da paciente optou-se pela realização de cirurgia renal percutânea à direita procurando-se preservar o pouco de função renal existente

Em virtude de antecipada recusa de possível hemotransfusão foram tomadas duas condutas hemoterápicas autólogas aceitas por esses fiéis em virtude de manterem conexão e interligação com o sistema venoso do paciente:

1) Hemodiluição: consiste em retirar um volume de sangue variável na dependência do hematócrito do paciente minutos antes do ato operatório. Esse sangue fica acondicionado com heparina em bolsas apropriadas e conectadas com o sistema venoso do paciente. Segue-se por outra via de aces- so a hiperidratação com soluções salinas objetivando hemodiluir seu sangue. Assim, o sangue perdido no ato operatório terá proporcionalmente uma menor concentração de glóbulos vermelhos. Ao término da cirurgia, o sangue total previamente retirado é rapidamente reinfundido. No caso ora relatado foi retirado uma bolsa de sangue que equivale a $400 \mathrm{ml}$.

2) Recuperação intraoperatória de sangue: consiste em aspirar através de conduto heparinizado o sangue da cavidade torácica, abdominal ou pélvica que é passado por uma máquina específica que faz as seguintes funções: 1 - filtragem: separa partículas ou microagregados maiores de 40 micras do conteúdo aspirado que são desprezadas. Também elimina microêmbolos gordurosos do sangue aspirado, sobretudo durante cirurgias ortopédicas; 2 centrifugação: processo pelo qual despreza-se o sobrenadante que inclui plasma, parte dos leucócitos e plaquetas; heparina e fatores de coagulação; 3 - lavagem de hemácias: com soro fisiológico; 4 -armazenamento: em sistema conectado na veia do paciente e pronto para reinfusão, assim que necessário, o que deverá ser feito em até 4 horas.

Como a cirurgia renal percutânea não permite o acesso do aspirador diretamente no retroperitôneo em virtude do pequeno corte que é feito na região lombar, foi idealizado uma pequena variação técnica que consiste em ocluir ao meio de sua capacidade um saco esterilizado de 60 litros e devidamente preso ao dorso da paciente com campo cirúrgico plástico colante. À medida que o sangue misturado com soro fisiológico saia pela bainha de Amplatz, caia no reservatório que era aspirado para a máquina (Figuras 1 e 2). Esse aparelho é manejado por pessoal médico e paramédico do banco de sangue e da empresa, devidamente treinados.

A cirurgia renal percutânea transcorreu sem anormalidades sendo realizadas duas punções renais para retirada do maior número de cálculos possível. Nas punções saiu urina purulenta. $\mathrm{O}$ volume coletado na máquina de recuperação intra-operatório de glóbulos vermelhos foi de $240 \mathrm{ml}$ e não foi reinfundido devido à presença de pus no líquido da punção.

1. Assistente do Serviço de Urologia do Hospital do Servidor Público do Estado de São Paulo; Urologista do Instituto de Medicina Humana Vitae IMUVI

2. Acadêmico de Medicina

Trabalho realizado no Instituto de Medicina Humana Vitae- IMUVI e no Hospital Santa Paula. 


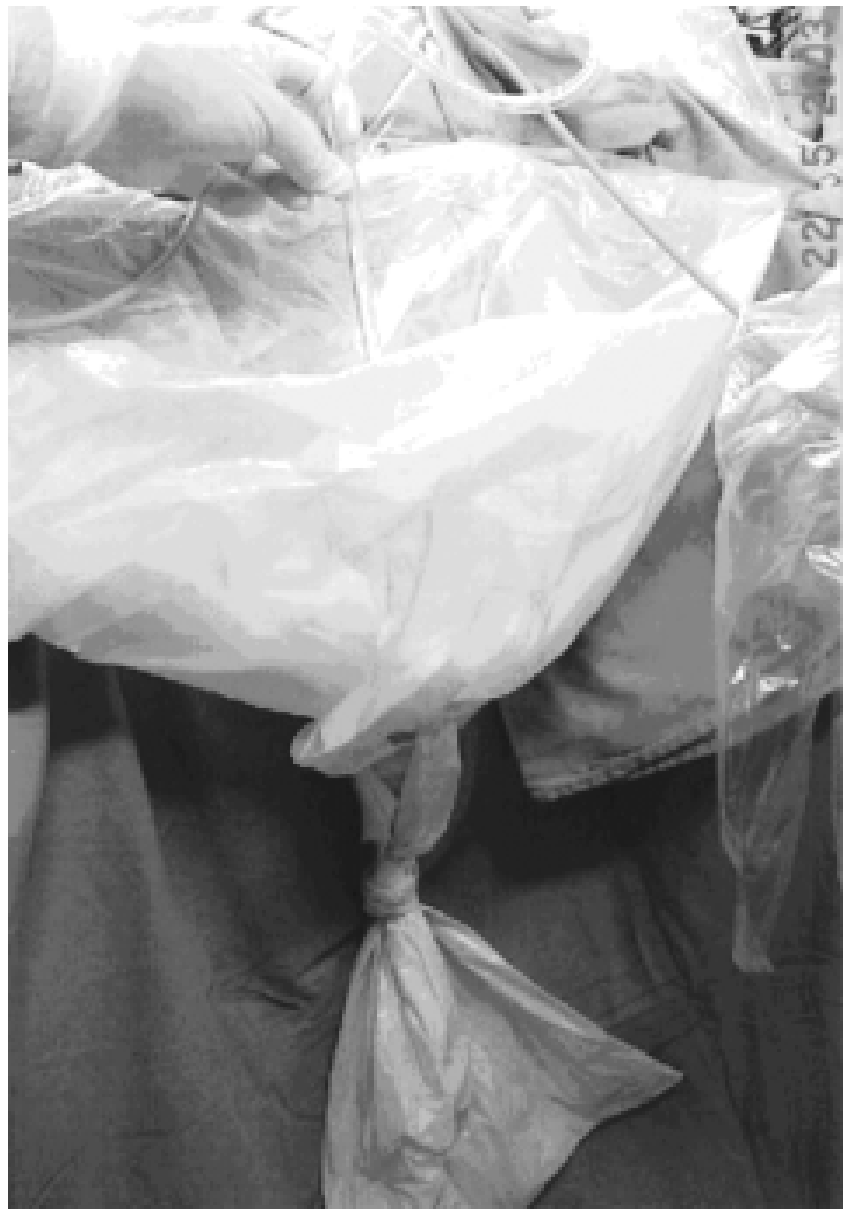

Figura 1 - Colocação de saco esterilizado de 60 litros com redução ao meio de sua capacidade, a fim de formar um reservatório para aspiração do sangue à máquina específica.

\section{DISCUSSÃO}

A hemotransfusão é um recurso terapêutico indispensável em muitas condições clínicas e cirúrgicas e, quando necessário, amplamente aceito pela grande maioria dos médicos e pacientes. A utilização de sangue heterólogo torna-se insubstituível diante de várias doenças. Entretanto, apesar dos rigores a que os bancos de sangue estão sujeitos não é um recurso totalmente livre de complicações.

A litíase do trato urinário poderá ou não estar associada a infecção. $\mathrm{O}$ cálculo coraliforme é geralmente causado por bactérias que possuem urease. Esta enzima transforma a uréia em amônia, tornando a urina alcalina e favorecendo a cristalização de fosfato amoníaco magnesiano (estruvita) e da apatita carbonato. A urocultura poderá revelar infecção urinária em 34 a $70 \%$ de pacientes com cálculo coraliforme ${ }^{2,3}$, fato esse não demonstrado no pré-operatório do presente caso.

A cirurgia renal percutânea, sobretudo no cálculo coraliforme, é um procedimento passível de complicações e, dentre elas, hemorragia intensa que pode obrigar à conversão para a abordagem a céu aberto. Técnicas de autotransfusão, portanto, devem ser sempre prioritariamente escolhidas.

No Brasil existem três máquinas de recuperação intraoperatória de sangue: 1 - Compact Advanced da Dideco de

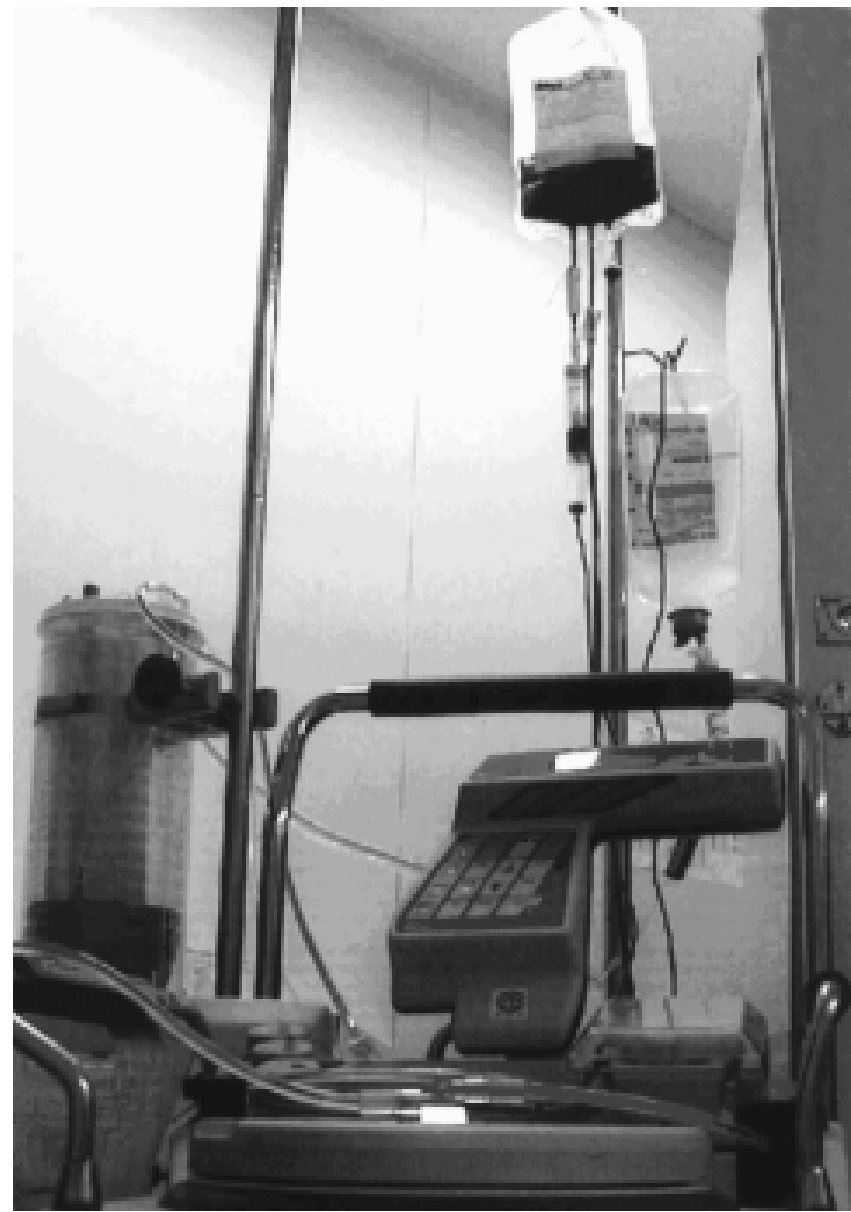

Figura 2 - Hemácias sendo acondicionadas em bolsa apropriada e em conexão com o sistema venoso da paciente.

procedência italiana e utilizada no presente caso; 2 - Cell Saver S da Haemotics de procedência norte-americana e 3) Cats da Frezenius de procedência alemã.

A recuperação intra-operatória de sangue deve ser contra-indicada em cirurgias oncológicas e infectadas, uma vez que a máquina não esteriliza o sangue a ser reinfundido. A irradiação com 50 Gy na bolsa de sangue obtida da recuperação intra-operatória de sangue em cirurgias oncológicas, torna a amostra isenta de células neoplásicas e, portanto, passível de reinfusão autóloga ${ }^{4,5}$. Na dúvida de infecção no sangue aspirado, pode-se lançar mão do esfregaço corado pelo Gram e da hemocultura.

A variação técnica utilizada de recuperação intra-operatória de sangue na cirurgia renal percutânea é simples e facilmente exequiível em qualquer hospital que realize esse tipo de procedimento.

\section{AGRADECIMENTOS}

Agradecemos ao Dr. Leandro de Pádua Santo Silva do Centro de Hemoterapia São Lucas do Hospital Santa Paula, e à biomédica Paula Cristina Frutuoso, assessora técnica da Politec, representante da Dideco no Brasil, pelas informações concedidas no intra e pós-operatório. 


\title{
ABSTRACT
}

\begin{abstract}
Jehova's witeness patients deny to receive heterologous blood transfusion even under life risk. They also neither agree with auto transfusion when the their own blood is stored days or weeks before surgery procedures. Percutaneous renal surgery can have complications and, among them, intense hemorrhage that can demand for open surgery. The authors report a case of a 32 year old patient with complete coralliform lithiasis in the right kidney who was submitted to percutaneous renal surgery with removing $400 \mathrm{ml}$ of total blood accompanied subsequently of hemodilution and blood reinfusion by the end of the procedure. A Compact Advanced from Dideco, an italian company, was used for blood recovering during surgery and reinfusing it after the filtration process, centrifugation and washing of red globules. In this particular, the authors describe a technical adaption for blood collection. Both procedures are accepted by Jehova's witness patients, once that the blood is not stored and there is contact with your veined system. This article aim to show a blood capture technical variant in the percutaneous renal surgery, as well as to present a method in similar procedures, once that is not used routinely in urological surgeries (Rev. Col. Bras. Cir. 2005; 32(5): 350-352).
\end{abstract}

Key words: Autohemotherapy; Hemodilution; Kidney/surgery; Lithiasis; Jehovah's witnesses.

\section{REFERÊNCIAS}

1. Zantut Lfc, Zantut Pec, Birolini D. Laparoscopia e autotransfusão em pacientes traumatizados. Estudo em 21 casos. Rev Col Bras Cir. 1991; 18(4):139-41.

2. Ruiz Marcellan FJ, Ibarz Servio L, Salinas Duffo D. Infective lithiasis. Treatment and complications. Arch Esp Urol. 2001; 54(9):937-50.

3. Benchekroun A, Lachkar A, Iken A, et al. La lithiase coralliforme. A propos de 98 cas. Ann Urol. 2000; 34(6):370-5.

4. Poli MC, Villa LL, Colella R, et al. Molecular evidence of tumour cell removal from salvaged blood after irradiation and leucocyte depletion. Transfus Med. 2004; 14(1):151-5.
5. Hansen E, Altmeppen J, Kutz N, et al. Intraoperative blood salvage with blood irradiation in cancer surgery (1186). In: Congress of the International Society of Blood Transfusion, 25, June 27 - July 2, 1998. Oslo.

Endereço para correspondência:

Rua Bias, 234

Tremembé

02371-020 - São Paulo - SP 